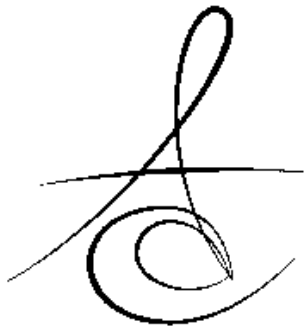

\title{
GELİ̧̧İMSEL MİNE DEFEKTLERİNİN TEDAVİSİNDE KULLANILAN ÇEŞİTLi் MATERYALLERİN RENK MASKELEME ETKİNLİĞİNİN GÖRSEL ve CİHAZ YÖNTEMİ ile DEĞERLENDİRİLMESİ
}

\author{
EVALUATION OF COLOR MASKING EFFECTIVENESS BY VISUAL AND \\ INSTRUMENTAL METHODS OF VARIOUS MATERIALS USED IN THE \\ TREATMENT OF DEVELOPMENTAL ENAMEL DEFECTS
}

\author{
Uzm. Dt. Mihriban Dudu Gizem GENÇER*
}

Prof. Dr Zuhal KIRZIOĞLU**

Makale Kodu/Article code: 3687

Makale Gönderilme tarihi: 23.05.2018

Kabul Tarihi: 13.07.2018

\section{öz}

Amaç: Çalışmamızda, gelişimsel mine defekti bulunan kesici dişlere sahip bireylerin estetik kaygları değerlendirilmiştir. Ayrıca, rezin infiltrant tedavisi ve mikroabrazyon ile birlikte uygulanan trikalsiyum fosfat ve kazeinfosfopeptid amorf kalsiyum fosfat remineralizasyon ajanlarının renk maskeleme etkinliğinin görsel ve cihaz yöntemi ile değerlendirilmesi amaçlanmıştır.

Gereç ve Yöntem: Çalışmaya, 8-17 yaş arası çalışma için belirlenen kriterlere uygun 1. grup Florozis Diş Yüzey İndeks 1-4 skor aralığındaki 128 florozis ve 2 . grup Modifiye Gelişimsel Mine Defekti İndeksi 1-5 skor aralığındaki 161 hipomineralizasyon görülen kesici dişe sahip hastalar dahil edilmiştir. Hastaların dişleri ile ilgili estetik kaygılarını değerlendirmek için Modifiye Çocuk Ağız ve Diş Sağlığı Etki Profili anketi uygulanmıştır. Tedavi uygulamasını kabul eden her 2 gruptaki hastalara, Icon $\AA$, Opalustre $\AA+$ Clinpro White Varnish $₫$ ve Opalustre $₫+$ Tooth Mousse $\AA$ tedavileri 3 alt grup halinde uygulanmıştır. Çalışmaya katılan dişlerin renk değerlendirmeleri için görsel analog skalası ve spektrofotometre $(\Delta \mathrm{E}$ değeri) kullanımışır. Sonuçlar istatistiksel olarak değerlendirilmiştir.

Bulgular: Estetik kaygı ile ilgili yapılan değerlendirmede, 1. grupta (florozis) remineralizasyon ajanları arasında estetik kaygı ile ilişkinin olmadığı belirlenmiștir $(p>0,05)$. 2. grupta (hipomineralizasyon) ise tüm remineralizasyon ajanlarında uygulamalarının sonucunda klinik olarak fark edilebilir değişiklik elde edildiği tespit edilmiştir $(p<0,05)$. Her 2 grupta da görsel analog skor değerleri en yüksek Icon ®’da elde edilmiştir.

$\Delta \mathrm{E}$ değerleri ise Grup 1'de (florozis) en yüksek Icon $\Omega^{\prime}$ da, Grup 2'de (hipomineralizasyon) ise en yüksek Icon ${ }^{\prime}$ 'da ve en düşük Opalustre $\AA+T o o t h$ Mousse ${ }^{\prime}$ ' da bulunmuştur.

Sonuç: Hipomineralizasyon grubunda estetik kaygı ön plana çıkmışır. Gelişimsel mine defekti görülen dişlerde rezin infiltrant ve mikroabrazyon uygulamalarının sonucunda, hem görsel analog skalası hem de spektrofotometre kullanılarak klinik olarak fark edilebilir değişiklik olduğu belirlenmiștir. Çalışmalarda görsel ve cihaz ile değerlendirmelerin sağlıklı yapılabilmesi için standardizasyonun sağlanması gerekmektedir.

Anahtar Kelimeler: Renk maskeleme, spektrofotometre, görsel analog skalası, estetik kaygı

\section{ABSTRACT}

Aim: In our study, the aesthetic concerns of the individuals with incisors with developmental enamel defects were evaluated. Also, it was aimed to evaluate the color masking effect of resin infiltrant treatment and 2 different remineralization agents tricalcium phosphate and caseinphosphopeptide amorphous calcium phosphate applied with microabrasion by visual and instrumental methods.

Material and method: Incisor teeth detected for the research of 8-17 ages are included in the study. The study is carried out by 2 groups based on the teeth 128 fluorosis observed between the scores of 1-4 within Tooth Surface Index of Fluorosis and 161 hypomineralization observed between the scores of 1-5 within Modified Developmental Defects of Dental Enamel Index. Modified Children's Oral and Dental Health Impact Profiles Questionnaire was applied to evaluate the aesthetic concerns of patients about their teeth. Patients in each of the two groups who accepted the treatment, Icon $\AA$, Opalustre $₫+$ Clinpro White Varnish $₫$ and Opalustre $\mathbb{R}+$ Tooth Mousse $\AA$ treatments were applied in 3 subgroups. Visual analogue scale and spectrophotometer $(\Delta \mathrm{E}$ value) were used for the color evaluations of the teeth participating in the study. The results were evaluated statistically.

Results: In evaluating the aesthetic concerns, it was determined that there was no relationship between fluorosis groups and aesthetic concerns.

It has been found that clinically noticeable changes are obtained as a result of all treatment applications in incisor teeth with developmental enamel defect. In both groups, visual analogue scores were obtained in the highest group $A$. $\Delta \mathrm{E}$ values were found in the highest group Icon ${ }^{\circledR}$ in the fluorosis group, in the highest group Icon $\AA$ and the lowest group Opalustre $\AA+$ Tooth Mousse $\AA$ in the hypomineralization group.

Conclusions: Aesthetic corcens has come to the forefront in the hypomineralization group. It has been determined that the teeth with developmental enamel defects are clinically noticeable changes, both by visual analogue scale and spectrophotometer, as a result of resin infiltrant and microabrasion applications. Standardization must be ensured so that visual and instrumental evaluations can be carried out in a healthy way during the studies.

Keywords: Color masking, spectrophotometer, visual analog scale, aesthetic concern

\footnotetext{
${ }^{*}$ Hakkari Ağız ve Diş Sağlığı Merkezi, Hakkari,

** Süleyman Demirel Üniversitesi Diş Hekimliği Fakültesi Pedodonti AD, Isparta.
} 


\section{GİRİŞ}

Florozis ve hipomineralizasyon, en sık görülen gelişimsel mine defektleri arasındadır. Floroziste, dış yüzey tabakası iyi mineralize iken, yüzey altı tabakada yaygın hipomineralizasyon veya porozite görülmektedir $^{1}$. Hipomineralizasyon ise, dokunun translüsensisi ile ilgili bir anomalidir. Her 2 defekt türünde, mine matriks oluşumu ve mine mineralizasyonu aşamalarında ameloblastların aktivitesinin baskılanması sonucu sarımsı/kahverengimsi alanlar görülmektedir ${ }^{2}$.

$\mathrm{Bu}$ gelişimsel mine defektlerinin özellikle üst çene ön dişlerinde ve gülme hattında bulunması nedeni ile oluşan estetik kaygının tedavi uygulamaları ile çözümlenmesi önem kazanmaktadır. Bu tip durumlarda uygulanan tedaviler, mikroabrazyon, beyazlatma, rezin infiltrasyon, direkt/indirekt kompozit restorasyonlar, kompozit rezin ve porselen veneerlerdir. Özellikle genç bireylerde estetik taleplerin karşılanması için gerekli en az invaziv yaklaşım benimsenmelidir.

Yapılan restorasyonların hekimler tarafından estetik açıdan değerlendirilmesi, hem görsel hem de cihaz yöntemi ile yapılmaktadır. Görsel renk değerlendirmesinde, hem klinik hem de araştırma şartlarında subjektif parametrelerin ölçülmesi için kolay, hassas, geçerli ve güvenilir olan renk skalaları ve görsel analog skalaları (VAS) kullanılmaktadı ${ }^{3,4}$. Görsel çalışmalarda hasta, hekim, fiziksel şartlar vb. birçok parametre bu değerlendirmeyi etkileyebileceği için göz önünde bulundurulmalıdır. Bu nedenle renk değerlendirmesinde, bu faktörleri ortadan kaldırabilmek ve standardizasyonun sağlanabilmesi için cihazlar kullanılmaktadır.

Renk değerlendirmesinde cihaz kullanımı; spektrofotometreler, kolorimetreler ve görüntüleme sistemleri ile yapılmaktadır ${ }^{5}$. Görünür spektrum boyunca 1-25 nm aralıklarla bir nesneden yansıyan ışık enerjisi miktarını ölçen spektrofotometreler, elde edilen ölçümleri sıklıkla diş ton kılavuzlarına dönüştürmektedir $^{6,7}$. Cihaz ile renk değerlendirmeleri, daha güvenilir ve tekrarlanabilir bir yöntem olup nesneden yansıyan ışı̆̆ın optik aletlerle değerlendirilmesine dayanmaktadır ${ }^{4}$.

Çocuk ve genç erişkinlerde, florozis ve hipomineralizasyona bağlı renklenmelerin estetik kaygıya neden olduğu bilinmektedir. Bu nedenle çalışmamızda hastaların estetik kaygıları değerlendirilmiştir.

Çalışmamızda, ayrıca gelişimsel mine defekti bulunan kesici dişlere rezin infiltrant tedavisi ve mikroabrazyon ile birlikte uygulanan 2 farklı trikalsiyum fosfat ve kazeinfosfopeptid amorf kalsiyum fosfat remineralizasyon ajanlarının renk maskeleme etkisinin görsel analog skalası ve spektrofotometre ile değerlendirilmesi amaçlanmıştır.

\section{GEREÇ ve YÖNTEM}

Çalışma öncesinde, S.D.Ü. Tıp Fakültesi Klinik Araştırmalar Etik Kurul Başkanlığı'ndan ilgili etik kurul onayları alınmıştır (27.05.2015 tarih ve 128 sayılı karar) ve Power analizi yapılmıştır. $a=0,05$ testin gücü 0,95 florozis ve hipomineralizasyon olan uygulamada, her bir gruptaki gözlem adedi sayısı 30 olarak tespit edilmiştir.

\section{Çalışma Grubunun Belirlenmesi:}

Kliniğimize başvurmuş 8-17 yaş arası hastalar muayene edilmiş ve kesici dişlerinde gelişimsel mine defekti bulunan hastaların bulguları formlara kaydedilmiştir. Gelişimsel mine defekti görülen hastalar florozis ve hipomineralizasyon olarak 2 gruba ayrılmıştır. Florozis grubu için, Florozis Diş Yüzey İndeksi (TSIF) sınıflaması ${ }^{8}$ kullanılmıştır. Hipomineralizasyon grubu için Gelişimsel Mine Defekti İndeksi'nin (GMDİ) ${ }^{9}$ ilk 5 skor, net sonuçlar elde etmek için servikal, orta ve insizal olmak üzere 3 alt gruba ayrılmıştır.

\section{Çalışmaya dahil edilme kriterleri;}

- Sağlıklı,

- Florozis Diş Yüzey İndeksine (TSIF) göre 1-4 skoru almış dişlere sahip,

- Modifiye Gelişimsel Mine Defekti İndeksine (MGMDİ) göre 1-5 skoru almış dişlere sahip,

- Simetrik ve benzer lezyon bulunan hastalardır.

Çalışmaya dahil edilmeme kriterleri;

- Uygulama yapılacak dişlerinde genetik ya da konjenital yapısal bozukluk bulunan,

- Uygulama yapılacak dişlerinde form bozukluğu olan,

- Ön segment diş dizisinde rotasyon ya da kapanış problemi bulunan,

- Uygulama yapılacak dişlerinde çürük lezyon veya önceden yapılmış restorasyonu olan,

- Uygulama yapılacak dişlerinde mikroabrazyon ya da beyazlatma tedavisi uygulanmış hastalardır.

Çalışmaya dahil olma kriterlerine sahip hastalara/ebeveynlerine, araştırma hakkında bilgi verilip yazılı gerekli izinler alınmıştır. Çalışma için gruplarda her skorda benzer sayıda diş ve diş grubu olacak şekilde dağılım yapılmıştır. Ayrıca formlarda, diş yüzeyi 9 bölgeye ayrılarak defektlerin lokalizasyonlarına göre kaydı alınmıştır (Resim 1). 


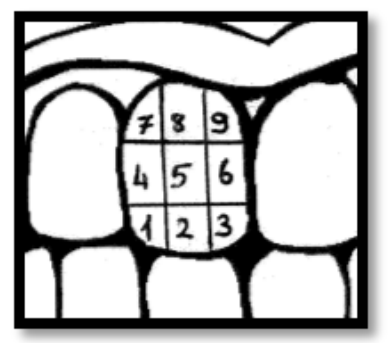

Resim 1. Dişlerdeki defektin bulunduğu yere göre lokalizasyonlarının kaydedilmesi

\section{Çalışma Grubuna Anketin Uygulanması:}

Çalışmayı kabul eden ve onam veren gelişimsel mine defekti görülen 289 diş (128 florozis ve 161 hipomineralizasyon görülen diş) bulunan 100 hastanın, estetik kaygılarını belirlemek için tedavi öncesi 11 sorudan oluşan Modifiye Çocuk Ağız ve Diş Sağlı̆ı Etki Profili (COHİP) ${ }^{10}$ anketi uygulanmış olup bilgileri formlara kaydedilmiştir (Tablo 1).

Tablo 1. Modifiye Çocuk Ağız Ve Diş Sağlığı Etki Profili (COHİP) Anketi

\begin{tabular}{|c|c|c|c|c|c|}
\hline & $\begin{array}{c}\text { Her } \\
\text { zaman }\end{array}$ & $\begin{array}{c}\text { Oldukça } \\
\text { sık }\end{array}$ & $\begin{array}{l}\text { Ara } \\
\text { sıra }\end{array}$ & $\begin{array}{c}\text { Neredeyse } \\
\text { hiçbir } \\
\text { zaman }\end{array}$ & Asla \\
\hline $\begin{array}{c}\text { 1. Dişlerindeki beyaz/sarı } \\
\text { renklenmeler } \\
\text { nedeniyle mutsuz } \\
\text { musun? }\end{array}$ & & & & & \\
\hline $\begin{array}{c}\text { 2. Dişlerindeki beyaz/sarı } \\
\text { renklenmeler } \\
\text { nedeniyle utangaç ya } \\
\text { da çekingen } \\
\text { davranıyor musun? }\end{array}$ & & & & & \\
\hline $\begin{array}{c}\text { 3. Dişlerindeki beyaz/sarı } \\
\text { renklenmeler } \\
\text { nedeniyle insanlarla } \\
\text { konuşmak istemediğin } \\
\text { oldu mu? }\end{array}$ & & & & & \\
\hline $\begin{array}{l}\text { 4. Dişlerindeki beyaz/sarı } \\
\text { renklenmeler } \\
\text { nedeniyle etrafında } \\
\text { başka insanlar varken } \\
\text { gülümsemek ya da } \\
\text { gülmekten kaçınıyor } \\
\text { musun? } \\
\end{array}$ & & & & & \\
\hline $\begin{array}{l}\text { 5. Dişlerindeki beyaz/sarı } \\
\text { renklenmeler } \\
\text { nedeniyle farklı } \\
\text { göründüğünü } \\
\text { hissediyor musun? }\end{array}$ & & & & & \\
\hline $\begin{array}{l}\text { 6. İnsanların dişlerindeki } \\
\text { beyaz/sarı } \\
\text { renklenmeler } \\
\text { nedeniyle } \\
\text { düşündüklerinden } \\
\text { endişe duyuyor } \\
\text { musun? }\end{array}$ & & & & & \\
\hline $\begin{array}{c}\text { 7. Dişlerindeki beyaz/sarı } \\
\text { renklenmeler } \\
\text { nedeniyle okula } \\
\text { gitmediğin günler oldu } \\
\text { mu? }\end{array}$ & & & & & \\
\hline
\end{tabular}

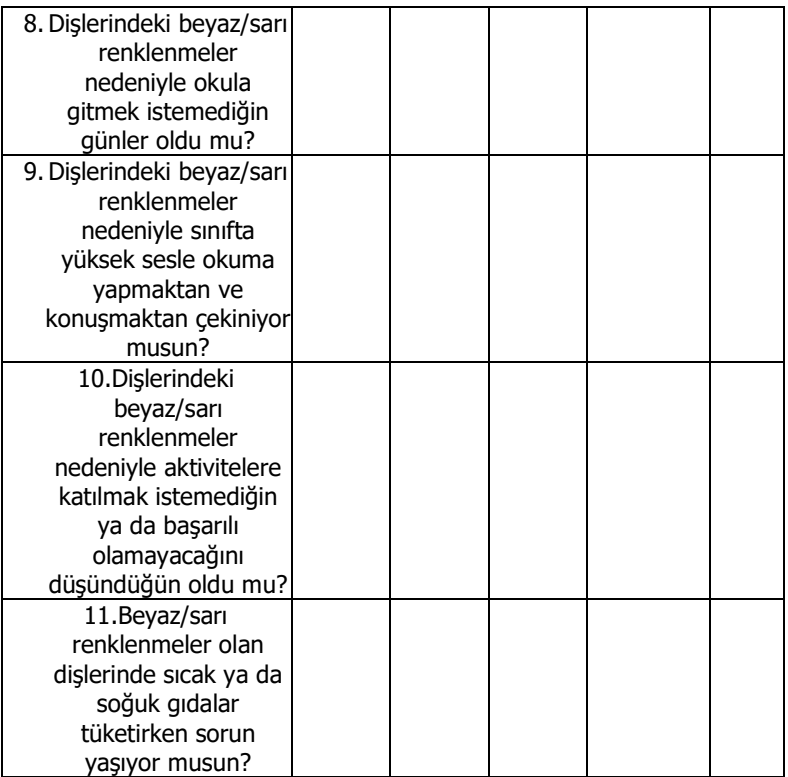

\section{Çalışma Grubuna Tedavilerin Uygulanması:}

Çalışmayı kabul edip sonradan tedavi uygulamasından vazgeçen hastalar olduğu için, uygulama 251 diş (103 florozis ve 148 hipomineralizasyon görülen diş) üzerinde yapılmıştır.

Hastaların uygulama yapılacak diş yüzeyi Softlex® (L502) (3M Espe, MN, Almanya) cila diski yardımı ile hazırlanmıştır. Tüm tedavi gruplarında ge- rekli koruyucu gözlükler kullanılmış ve dudaklar ekarte edilerek dişlerin izolasyonu sağlanmıştır. Dişeti korunması için ayrıca Opaldam ${ }^{\circledR}$ (Ultradent Products, South Jordan, UT, Amerika Birleşik Devletleri) uygulanmıştır.

Çalışmaya dahil edilen hastaların florozis ve hipomineralizasyon görülen kesici dişlerine, rezin infiltrant tedavisi Icon $\circledast$ (DMG, Hamburg, Almanya), mikroabrazyon tedavisi Opalustre $\AA$ (Ultradent Products, South Jordan, UT, Amerika Birleşik Devletleri) sonrası trikalsiyum fosfat (TCP) Clinpro White Varnish $\mathbb{R}$ (3M Espe, Seefeld, Almanya) ve mikroabrazyon tedavisi Opalustre ${ }^{\circledR}$ sonrası kazeinfosfopeptid amorf kalsiyum fosfat (CPP-ACP) Tooth Mousse ${ }^{\circledR}$ (GC Corporation, Tokyo, Japonya) tedavileri aynı hekim tarafından klinikte üretici firma talimatları doğrultusunda uygulanmışıı (Tablo 2).

\section{Görsel ve Spektrofotometre ile Renk}

\section{Değerlendirmesi}

Çalışmaya tedavi için randevusuna gelen hastaların 251 dişi (103 florozis ve 148 hipomineralizasyon görülen diş) görsel ve spektrofotometre ile değerlendirilmiştir. Görsel ve spektrofotometre 
ölçümlerinin güvenirliği için uygulayıcı farklı zamanlarda ve kendi içinde ölçümlerini tekrarlamıştır.

Tablo 2. Çalışma gruplarının dağıımı ve uygulanan tedavi basamakları

\begin{tabular}{|c|c|c|c|}
\hline & GRUP A & GRUP B & GRUP C \\
\hline $\begin{array}{c}\text { ÇALIŞMA } \\
\text { GRUPLARI }\end{array}$ & $\begin{array}{l}\text { Rezin İnfiltrant } \\
\text { Tedavisi } \\
\text { (Icon } ® \text { ) }\end{array}$ & $\begin{array}{c}\text { Mikroabrazyon }+ \\
\text { Trikalsiyum } \\
\text { Fosfat Tedavisi } \\
\text { (Opalustre } ₫+ \\
\text { Clinpro White } \\
\text { Varnish } ₫ \text { ) }\end{array}$ & \begin{tabular}{|} 
Mikroabrazyon+ \\
Kazeinfosfo-peptid \\
Amorf Kalsiyum \\
Fosfat Tedavisi \\
(Opalustre $₫+$ \\
Tooth Mousse $®$ )
\end{tabular} \\
\hline $\begin{array}{l}\text { GRUP 1: } \\
\text { Florozis } \\
\text { Grubu } \\
\text { (103 diş) }\end{array}$ & $\begin{array}{c}\text { 1. Icon-Etch } 2 \mathrm{dk} \\
\text { Yikama-kurulama } 30 \\
\text { sn } \\
\text { Icon-Dry } \\
30 \mathrm{sn} \\
\text { (1. basamak } 3 \text { kere } \\
\text { tekrar edilmiştir) } \\
\\
\text { 2. Icon-Infiltrant 3dk } \\
\\
\text { 3. LED ısık cihazı (T } \\
\text { LED, Sternweber, } \\
\text { 700nm) ile } 40 \mathrm{sn} \\
\text { polimerizasyon }\end{array}$ & $\begin{array}{c}\text { 1. Opalustre } 60 \mathrm{sn} \\
\text { Yikama-kurulama } \\
30 \mathrm{sn} \\
\text { 1.basamak } 5 \text { kere } \\
\text { tekrar edilmiştir) } \\
\begin{array}{c}\text { 2. Clinpro White } \\
\text { Varnish }\end{array}\end{array}$ & \begin{tabular}{|} 
1. Opalustre $60 \mathrm{sn}$ \\
Yikama-kurulama 30 \\
sn \\
1.basamak 5 kere \\
tekrar edilmiştir) \\
\\
2. Tooth Mousse \\
$3 \mathrm{dk}$
\end{tabular} \\
\hline $\begin{array}{c}\text { GRUP 2: } \\
\text { Hipominerali- } \\
\text { zasyon } \\
\text { Grubu } \\
\text { (148 diş) }\end{array}$ & 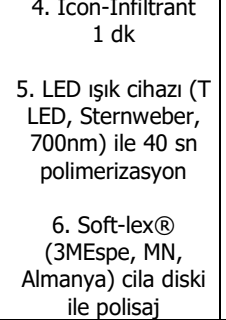 & & \\
\hline
\end{tabular}

Renk değerlendirmesi için işlem öncesi ve sonrası fotoğraf kayıtları alınmış, görsel analog skalası $(V A S)^{11}$ kullanılarak 0-7 aralığında skorlanmıştır. Ölçümler için, doğal ışığın girmediği, gün ışığını taklit edebildiği belirtilen ${ }^{12}$ D65 floresan lamba ile aydınlatılmış oda kullanılmıştır. Reflektör aydınlatması yapılmayan odada, kayıt alınan ünitin, koltuğun ve başın yerleştirildiği yer sabitlenmiştir.

Spektrofotometre ile renk değerlendirmesi Vita Easyshade Advance ${ }^{\circledR}$ (Vita Zahnfabrik, Almanya) ile üretici firma önerileri doğrultusunda aynı oda ve şartlarda, aynı hekim tarafından yapılmıştır. Spektrofotometre ile ölçümlerde her diş üzerinde özel şablonlar oluşturularak kayıtlar alınmış ve bu şablon ile aynı noktalardan ölçümler işlem öncesi ve sonrası yapılmıştır. Cihaz ölçümleri için, CIE L*a* ve b* sistemi kulanılarak her diş için $L^{*}, a^{*}$ ve $b^{*}$ değerleri kaydedilmiştir. $\Delta \mathrm{E}=\left[\left(\Delta \mathrm{L}^{*}\right)^{2}+\left(\Delta \mathrm{a}^{*}\right)^{2}+\left(\Delta \mathrm{b}^{*}\right)^{2}\right]^{1 / 2}$ formülü kullanılarak ${ }^{4}$ renk farklılıklarının büyüklüğü $(\Delta \mathrm{E})$ klinik açıdan değerlendirilmiştir.

\section{İstatistiksel Değerlendirme}

İstatistiksel değerlendirme, Statistical Package for Social Science Version 23.0 (SPSS) (Chicago, IL, 2015) programı kullanılarak yapılmıştır.

Çalışmada florozis grubu hastalara yönlendirilmiş estetik kaygı ile ilgili soruların ortalaması alınarak bu ortalamalar TSIF faktörünün seviyeleri dikkate alınarak tek yönlü varyans analizi ile karşılaştırımıştır. Hipomineralizasyon grubu hastalara yönlendirilmiş estetik kaygı ile ilgili soruların ortalaması alınarak bu ortalamalar MGMDİ faktörünün seviyeleri dikkate alınarak tek yönlü varyans analizi ile karşılaştırılmıştır.

Florozis ve hipomineralizasyon hasta gruplarında, uygulayıcının tutarlılığının belirlenmesi için Kappa katsayısı kullanılmıştır.

Görsel renk değerlendirme özelliği bakımından elde edilen veriler florozis ve hipomineralizasyon gruplarında parametrik olmayan Kruskal Wallis testi kulanılarak analiz edilmiştir ve verilen skorların ortalaması alınarak bu ortalamalar materyal faktörünün seviyeleri dikkate alınarak tek yönlü varyans analizi ile karşılaştırılmıştır.

Spektrofotometre ile renk değerlendirmeleri florozis ve hipomineralizasyon gruplarında $\Delta \mathrm{E}$ değerleri bakımından istatistiksel olarak değerlendirilmiştir. Her 2 gruptaki hastalardan hesaplanan $\Delta \mathrm{E}$ değerleri bakımından elde edilen veriler faktöriyel düzende tekrarlanan ölçümlü varyans analizi tekniği ile analiz edilmişlerdir.

\section{BULGULAR}

Gelişimsel mine defektlerinin neden olduğu estetik kaygıların değerlendirilebilmesi için hastalara işlem öncesi sorular yönlendirilmiştir. Florozis grubunda sorulara verilen cevapların ortalamaları alınarak bu ortalama değerler üzerinden TSIF gruplarının karşılaştırılmasında tek yönlü varyans analizi uygulanmış ve yapılan varyans analizi sonucunda TSIF gruplarının ortalamaları arasındaki fark istatistiksel olarak önemli bulunmamıştır ( $p>0,05$ ) (Tablo 3 ).

Hipomineralizasyon grubunda sorulara verilen cevapların ortalamaları alınarak bu ortalama değerler üzerinden MDMGI karşılaştırılmasında tek yönlü varyans analizi uygulanmış ve yapılan varyans analizi sonucunda MDMGİ gruplarının ortalamaları arasındaki fark istatistiksel olarak önemli bulunmuştur $(p<0,05)$ (Tablo 3). 
Tablo 3. Florozis ve hipomineralizasyon grubunda estetik kaygı değerlendirmesi için hastalara yönlendirilmiş sorulara verilen cevapların ortalamalarının TSIF ve MGMDİ grupları ile karşılaştırıması

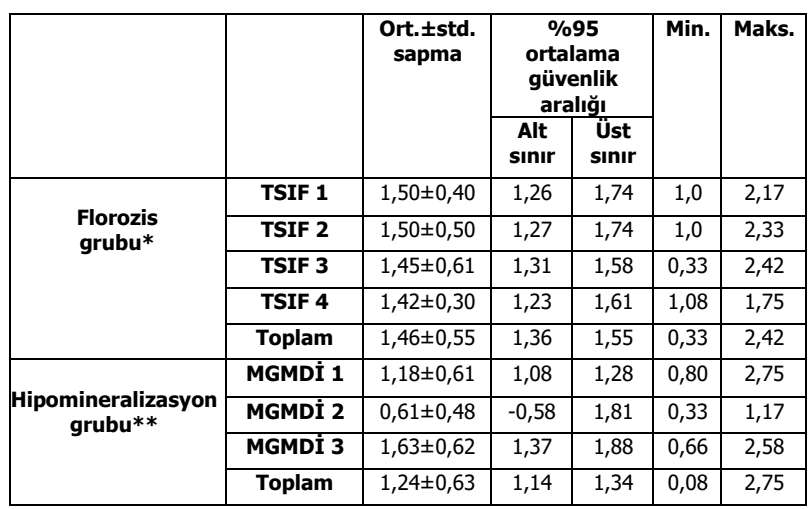

$* p>0,05, * * p<0,05$

Gelişimsel mine defektlerinin etiyolojisi açısından kaydedilen formlar değerlendirildiğinde, hipomineralizasyon grubunun, \%31,9'unda büyük azı keser hipomineralizasyonu (BAKH) olduğu ve \% 5,6' sında ise süt dişi enfeksiyonu ya da travması bulunduğu belirlenmiştir.

Çalışmada tedavi görmek istemeyen hastalar çalışma dışına çıkarılarak 103 florozis ve 148 hipomineralizasyon görülen toplam 251 dişe uygulama yapılmıştır. Uygulayıcının Kappa katsayısı, florozis grubunda 0,94 , hipomineralizasyon grubunda ise 0,88 olarak bulunmuştur.

Florozis grubu, görsel renk değerlendirme özelliği bakımından elde edilen veriler Kruskal Wallis testi kullanılarak analiz edilmiş ve materyallerin Rank ortalaması arasındaki farklılık istatistiksel olarak önemli bulunmuştur $(p<0,01)$ (Tablo 4$)$. Icon $®$ grubunda en yüksek değer elde edilmiştir, diğer gruplar arasında anlamlı bir farklılık bulunmamıştır.

Hipomineralizasyon grubunda görsel değerlendirme özelliği bakımından elde edilen veriler Kruskal Wallis testi kullanılarak analiz edilmiş ve materyallerin Rank ortalaması arasındaki farklılık istatistiksel olarak önemli bulunmuştur $(p<0,01)$ (Tablo 4). En yüksek

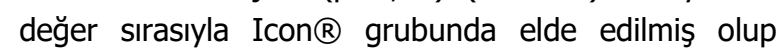
bunu Opalustre $\AA+$ Tooth Mousse $\AA$ ve Opalustre $\AA$ + Clinpro White Varnish $®$ grupları takip etmektedir.

Klinik olarak renk değişikliğinin değerlendirilmesi için kullanılan diğer yöntem olan spektrofotometre ile $\Delta \mathrm{E}$ değeri istatistiksel olarak değerlendirilmiştir. Florozis grubunda $\Delta \mathrm{E}$ değerleri bakımından elde edilen verilere yapılan varyans analizi sonucunda zaman ve materyal etkileşimi istatistiksel olarak önemli bulunmuştur $(p<0,01)$. Yapılan Tukey testi sonuçları Tablo $5^{\prime}$ te gösterilmiştir. İşlem sonrası en yüksek $\Delta \mathrm{E}$ değeri Icon $®$ grubunda elde edilmiştir. Diğer gruplar arasında anlamlı farklılık bulunmamıştır.

Hipomineralizasyon grubunda $\Delta \mathrm{E}$ değerleri bakımından elde edilen verilere yapılan varyans analizi sonucunda zaman ve materyal etkileşimi istatistiksel olarak önemli bulunmuştur $(p<0,01)$. Yapılan Tukey testi sonuçları Tablo $5^{\prime}$ te gösterilmiştir. İşlem sonrası en düşük $\Delta \mathrm{E}$ değeri Opalustre $\AA+$ Tooth Mousse $\AA$ grubunda elde edilmiştir. Diğer gruplar arasında anlamlı farklılık bulunmamıştır.

Tablo 4. Florozis ve hipomineralizasyon grubunun materyallere göre görsel renk değerlendirmelerinin Rank ortalamaları

\begin{tabular}{|c|c|c|}
\hline & Materyal & Ort. Rank \\
\hline \multirow{2}{*}{$\begin{array}{c}\text { Florozis Grubu } \\
\text { Görsel Renk } \\
\text { Değerlendirmesi* }\end{array}$} & Icon(n=38) & $70,39 \mathrm{~A}$ \\
\cline { 2 - 3 } & Clinpro(n=34) & $47,96 \mathrm{~B}$ \\
\cline { 2 - 3 } $\begin{array}{c}\text { Hipomineralizasyon } \\
\text { Grubu Görsel Renk } \\
\text { Değerlendirmesi* }\end{array}$ & Icon(n=49) & $104,95 \mathrm{~A}$ \\
\cline { 2 - 3 } & Clinpro(n=49) & $48,39 \mathrm{C}$ \\
\cline { 2 - 3 } & Tooth Mousse(n=50) & $70,25 \mathrm{~B}$ \\
\hline \multirow{2}{*}{$\boldsymbol{p}<\mathbf{0 , 0 1}$}
\end{tabular}

Tablo 5. Florozis ve hipomineralizasyon grubu $\Delta \mathrm{E}$ değerlerinin materyal-zaman etkileşimi ortalama ve standart hata verileri

\begin{tabular}{|c|c|c|}
\hline & Materyal & $\begin{array}{c}\text { Ort. } \mathbf{c} \text { Std. } \\
\text { hata }\end{array}$ \\
\hline \multirow{2}{*}{$\begin{array}{c}\text { Florozis } \\
\text { grubu }\end{array}$} & Icon(n=38) & $13,14 \mathrm{a} \pm 0,76$ \\
\cline { 2 - 3 } & Clinpro(n=34) & $7,92 \mathrm{~b} \pm 0,80$ \\
\cline { 2 - 3 } & Tooth Mousse(n=31) & $8,00 \mathrm{~b} \pm 0,84$ \\
\hline \multirow{3}{*}{$\begin{array}{c}\text { Hipomineralizasyon } \\
\text { grubu }\end{array}$} & Icon(n=49) & $12,77 \mathrm{a} \pm 1,03$ \\
\cline { 2 - 3 } & Clinpro(n=49) & $11,09 \mathrm{a} \pm 1,03$ \\
\cline { 2 - 3 } & Tooth Mousse(n=50) & $7,04 \mathrm{~b} \pm 1,02$ \\
\hline
\end{tabular}

* Küçük harfler işlem sonrası materyaller arasındaki farklıığı göstermektedir.

\section{TARTIŞMA}

Modern diş hekimliğinde hastaların dental intiyaçları, fonksiyon ve estetik olarak kabul edilmektedir. Diş rengi, hastaların restorasyonları değerlendirmesinde en önemli faktör olarak görülmektedir. Çalışmamız dişlerinde florozis ve hipomineralizasyon görülen hastalar üzerinde yürütülmüştür. Çalışmamızda bu grup hastaların estetik açıdan kaygıları olduğu belirlenmiş olup hastaların estetik kaygılarını değerlendirmek için Modifiye Çocuk Ağız ve Diş Sağlığı Etki Profili (COHIP) anketi ${ }^{10}$ hastalar tarafından doldurulmuştur. Diş renginde farklılıkların olmaması ve estetiğin sağlanması çocuk ve genç erişkinler için 
önemlidir. Diş hekimlerinin bu grup hastaların ihtiyaçlarını ve tedavi beklentilerini daha iyi karşılamak amacıyla bu defektlerin bireylere olan etkilerine önem vermesi gereklidir.

Gelişimsel mine defektlerinin psikososyal etkileri ile ilgili birçok anket uygulanmaktadır. Çoğunlukla çalışmalar daimi dişlerinde florozisi olan çocuklarda yapılmışıır ${ }^{13}$ ve az sayıda amelogenezis imperfekta ile ilgili çalışma mevcuttur ${ }^{14}$. Florozis ile ilgili yapılan çalışmada, florozisi olan hastaların dişlerinin görünümünden çok fazla memnuniyetsizlik duydukları belirlenmiştir $^{15}$. Buna karşılık bu grup hastaların, memnun olduklarını bildirdikleri bir çalışma da mevcuttur ${ }^{16}$.

Çalışmamızda florozis grubu hastalarda estetik kaygı etkinliğinin değerlendirilmesinde anlamlı fark bulunmamıştır. Bu gruba dahil edilen hastaların, TSIF 1-4 skor aralığındaki madde kaybı olmayan ve koyu renklenme gözlenmeyen dişlerin dahil edilmesi, benzer bölgede yaşayan, benzer sosyodemografik yapıya sahip ve aynı okula giden çocuk ve genç erişkinlerin dahil edilmesine bağlı olduğu düşünülmüştür. Ayrıca ilimizde erişkin bireylerin skoru yüksek florozisli dişlere sahip olması bu grupta estetik kaygı oluşmasını engellemiş olabilir. Buna karşın hipomineralizasyon grubunda bu şartlar olmadığı için anlamlı farklılık görülmemiştir.

Gelişimsel mine defekti görülen genç bireylerde estetik talep bulunmaktadır ve Isparta ilimiz endemik florozis bölgesidir. Çalışmamızda bu durum göz önünde bulundurularak tedavi gruplarının florozis ve hipomineralizasyon görülen hastalar olmasına karar verilmiştir. Hipomineralizasyon görülen hastalarda olası etiyolojik faktörler hasta formları kaydedilerek belirlenmeye çalışılmıştır. Anket soruları hafızaya dayalı olup her ebeveyn doğru hatırlayamamaktadır. Bu durum göz önünde bulundurularak sorular 2 kere sorulmuş ve cevaplar değerlendirildiğinde, hastaların $\% 31,9$ 'unda BAKH olduğu ve \% 5,6'sında süt dişi enfeksiyonu ya da travmasına bağlı oluştuğu belirlenmiştir. Soruların yanıltıcı olabileceği düşünüldüğünden etiyolojik faktörlere bağlı renk maskeleme özelliğinin değerlendirilmesinden vazgeçilmiş ve hipomineralizasyon görülen dişlerde tek grupta çalışılmıştır.

Çalışma grubumuzda diş yüzeyinde madde kaybı olmayan dişler florozis grubunda TSIF ve hipomineralizasyon grubunda MGMDİ indeksleri kullanılarak dahil edilmiştir. Şiddetli olmayan florozis olgularında, mikroabrazyon uygulamaları tercih edilmektedir $^{17}$ ve rezin infiltrant tedavisinin de bu hasta gruplarında başarı ile uygulanabileceğini gösteren sınırlı sayıda çalışma belirtilmektedir ${ }^{18,19}$. Diğer çalışma grubumuz olan hipomineralizasyon grubu hastalarla ilgili yapılan çalışmalarda, mikroabrazyon ve rezin infiltrant tedavilerinin, renk maskeleme etkinliğinin etiyolojik faktörlere bağlı olarak değiştiği bildirilmiştir ${ }^{19-21}$. Her 2 grup hastada rezin infiltrant tedavisinin renk maskelemesi özelliği ile ilgili çalışmalar yapılmasına karşılık, mikroabrazyon tedavisini takiben TCP ve CPP-ACP uygulaması sonrası renk maskeleme etkinliğini araştıran çalışmaya erişilebilen kaynaklarda rastlanmamıştır. Bu çalışmada remineralizasyon ajanlarının mikroabrazyon tedavisi sonrası renk maskeleme özelliği olup olmadığı araştırılmaya çalışılmıştır.

Çalışmamızda tedavi uygulamaları sonrasında renk maskeleme etkinliğinin işlem sonrası değerlendirilmesi için hem görsel hem de cihaz ile değerlendirme yapılmıştır. Görsel yöntemde, oluşabilecek subjektif farklılıklar nedeniyle diş renginin belirlenmesinde standardizasyonun sağlanmasında zorluklar yaşanılmaktadır ve yanılma payı söz konusudur. Bu nedenle cihaz kullanımı net ve bilimsel sonuçlar verecektir. Çalışmamızda tedavi gruplarının renk maskeleme özelliklerinin değerlendirilmesinde, birbirlerini tamamlayan ve öngörülebilir estetik sonuca yol açan görsel değerlendirme ve spektrofotometre ile renk değerlendirme yöntemleri beraber kullanılmıştır ${ }^{22}$. Görsel değerlendirmenin yanısıra kullanılan, in vivo ve in vitro şartlarda güvenilir olarak belirtilen spektrofotometreler ile daha tutarlı, objektif renk değerlendirmesi sağlanmakta ve kesin nicel veriler elde edilmektedir ${ }^{23}$. Çalışmamızda cihaz ile renk ölçümü için in vivo şartlarda hassas olduğu belirtilen Easyshade spektrofotometresi kullanılmıştır ${ }^{24}$. Easyshade spektrofotometresinin görsel değerlendirmeye göre daha karşılaştırılabilir sonuçlar verdiği ve performansının daha iyi olduğu bildirilen çalışmalarda, görsel değerlendirme arasındaki uyumu iyi bulunmuştur ${ }^{25,26}$. Çalışmamızda görsel ve cihaz ile yapılan renk değerlendirmesinde, standardizasyonun sağlanması için doğal ışığın girmediği özel bir oda hazırlanmıştır.

Görsel değerlendirmede, renk skalaları ve VAS kullanılmaktadır. Çalışmamızda görsel değerlendirme için hazırlanan odada fotoğraf kayıtları alınarak VAS ile değerlendirme yapılmıştır ve dişte meydana gelen değişiklikler skalanın 1-7 arası skorlarında kaydedilmiştir. Rezin infiltrant ve özellikle mikroabrazyon tedavisi sonrası uygulamanın değerlendirilmesinde hem klinik 
olarak hem de fotoğraf kaydı alınarak bu skorlamanın kullanıldığı benzer çalışmalar mevcuttur ${ }^{11,27-29}$. Bu çalışmalarda, florozis olgularında mikroabrazyon tedavisi başarılı bulunmuştur. Rezin infiltrantın başlangıç çürük lezyonları üzerine etkinliğinin VAS ile değerlendirildiği çalışmada da klinik görünüm düzelmiştir. Çalışmamızda kullanılan materyallerin VAS ile değerlendirildiği erişilebilir kaynak bulunmamaktadır. Çalışmamız sonucunda VAS ile yapılan değerlendirmede her 2 grupta en başarılı tedavi rezin infiltrant olmuştur.

Görsel değerlendirmenin yanısıra kullanılmakta olan cihaz ile renk ölçümlerinde, homojen bir renk uzayı oluşturarak diş renginin algısı ve değerlendirilmesi için en sık kullanılan sistemlerden biri CIE L*a*b* sistemidir ${ }^{24}$. Çalışmamızda, bu sisteme göre spektrofotometre ile $L^{*} a^{*}$ ve $b^{*}$ değerleri kaydedilerek formül ile $\Delta \mathrm{E}$ değerleri hesaplanmıştır. Vestibül diş yüzeyinin orta eksen boyunca lokalizasyonlara ayrılarak $L^{*}$, a* ve b* değerlerinin ölçüldüğü bir çalışmada, servikal ve insizal bölgede ölçüm değerlerinin değiştiği ve orta üçlüde yapılan ölçümlerin en tutarlı sonuçlar verdiği bildirilmiştir ${ }^{30,31}$. Çalışmamızda, ölçüm yapılacak dişlerin vestibül yüzeyleri 9 lokalizasyona ayrılmış, orta üçlünün ortasına denk gelen 5 bölgesinde yer alan yüzeylerden spektrofotometre ile şablonlar aracilığıla ölçümler yapılmıştır. Seçilen her diş için hazırlanan özel şablon ile referans noktaları belirlenerek işlem öncesi ve sonrası kullanılmış ve yanıltıcı ölçümlerin önüne geçilmeye çalışıımıştır. Çalışmamızda kullandığımız spektrofotometre diş yüzeyinde tek yüzey ölçümü yapmakta olup diş yüzeyinde belirlenen defekt lokalizasyonlarının ölçümü, cihaz ucunun çapı kadar ölçülerek değerlendirilip $\Delta \mathrm{E}$ değeri hesaplanmıştır.

Cihaz ile yapılan ölçümlerde herhangi bir alandaki değişikliğin klinik olarak belirlenebilmesi için $\Delta \mathrm{E}$ eşik değerinin ' $>3,7$ ' biriminde olması belirtilmiştir ve iki farklı zamanda renk değişikliğin büyüklüğünü hesaplamak için kullanılmaktadı ${ }^{32,33}$. Çalışmamızda, renk değişikliğinin kabul edilebilirliği olan eşik değer $\Delta \mathrm{E}$, florozis ve hipomineralizasyon grubunda yer alan tüm tedavi gruplarında $>3,7$ bulunmuştur. Bu sonuç ile işlem sonrası her materyalin renk maskelemesi sağladığı düşünülmüştür. Bu değer ile ilgili başlangıç çürük lezyonlarında yapılan in vitro çalışmalarda rezin infiltrant grubunda $\Delta \mathrm{E}$ değerinde farklı sonuçlar elde edilmiş olup $\Delta \mathrm{E}$ değerinin arttığı ve azaldığı çalışmalar mevcuttur ${ }^{34-36}$. Mikroabrazyon ile ilgili yapılan bir çalışmada ise, tedavi sonrası $\Delta \mathrm{E}$ değerinde artış gözlenmiştir $^{34}$. Başlangıç çürüklerinde yapılan in vivo çalış- malarda ise; rezin infiltrant ve mikroabrazyon tedavileri sonrası $\Delta \mathrm{E}$ değerlerinin arttığı görülmüştür ${ }^{37,38}$. Çalışmamızda, florozis grubunda en yüksek renk değişikliği rezin infiltrant grubunda olmuştur. Hipomineralizasyon grubunda, CPP-ACP tedavisinde eşik değerin üzerinde değer elde edilmesine karşın en düşük renk değişikliği görülmüştür. Bu sonuçlara göre rezin infiltrant tedavisinin en etkili tedavi olabileceği söylenebilir.

Çalışmamızda gelişimsel mine defektlerinde kullanılan tedavi grupları içinde rezin infiltrant tedavisinin daha etkin olduğu görülmüştür. Geçen süre içinde oral koşullarda meydana gelen değişikliklerin materyal etkinliği üzerine etkisi izlenmeli ve etkinliğin ne kadar süre ile sağlanabileceği değerlendirilmelidir.

\section{SONUÇ}

Gelişimsel mine defekti görülen dişlerde estetik kaygı için sosyoekonomik ve çevresel faktörlerin önemi görülmüş, florozis grubuna karşın hipomineralizasyon grubunda estetik kaygı ön plana çıkmıştır.

Rezin infiltrant ve mikroabrazyon uygulamalarının sonucunda hem görsel analog skalası hem de spektrofotometre kullanılarak klinik olarak fark edilebilir değişiklik olduğu belirlenmiştir. Çalışmalarda görsel ve cihaz ile değerlendirmelerin sağlıklı yapılabilmesi için standardizasyonun sağlanması gerekmektedir.

M.D. Gizem Gençer: ORCID ID: 0000-0003-4215-6946 Zuhal Kırzıoğlu:ORCID ID: 0000-0002-8398-3262

\section{KAYNAKLAR}

1. Yanagisawa $\mathrm{T}$, Takuma $\mathrm{S}$, Fejerskov $\mathrm{O}$. Ultrastructure and composition of enamel in human dental fluorosis. Adv Dent Res 1989; 3:203-10.

2. Garg N, Jain AK, Saha S, Singh J. Essentiality of early diagnosis of molar incisor hypomineralization in children and review of its clinical presentation, etiology and management. Int J Clin Pediatr Dent 2012; 5:190-6.

3. Katz J, Melzack R. Measurement of pain. Surg Clin North Am 1999; 79:231-52.

4. O'Brien WJ. Dental materials and their selection. 3rd ed. Chicago; Quintessence Publishing: 2002.

5. Chu SJ, Trushkowsky RD, Paravina RD. Dental color 
matching instruments and systems. Review of clinical and research aspects. J Dent 2010; 38:e216.

6. Khurana R, Tredwin CJ, Weisbloom M, Moles DR. A clinical evaluation of the individual repeatability of three commercially available colour measuring devices. Br Dent J 2007; 203:675-80.

7. Lagouvardos PE, Fougia AG, Diamantopoulou SA, Polyzois GL. Repeatability and interdevice reliability of two portable color selection devices in matching and measuring tooth color. J Prosthet Dent 2009; 101:40-5.

8. Horowitz HS, Driscoll WS, Meyers RJ, Heifetz SB, Kingman A. A new method for assessing the prevalence of dental fluorosis--the Tooth Surface Index of Fluorosis. J Am Dent Assoc 1984; 109:3741.

9. Clarkson J, O'Mullane D. A modified DDE Index for use in epidemiological studies of enamel defects. J Dent Res 1989; 68:445-50.

10. Broder HL, McGrath C, Cisneros GJ Questionnaire development: face validity and item impact testing of the Child Oral Health Impact Profile. Community Dent Oral Epidemiol. 2007; 35:8-19.

11. Price RB, Loney RW, Doyle MG, Moulding MB. An evaluation of a technique to remove stains from teeth using microabrasion. J Am Dent Assoc 2003; 134:1066-71.

12. Van Trigt C. Color rendering, a reassessment. Col Res Appl 1999; 24:197-206.

13. Chankanka O, Levy SM, Warren JJ, Chalmers JM. A literature review of aesthetic perceptions of dental fluorosis and relationships with psychosocial aspects/oral health-related quality of life. Community Dent Oral Epidemiol 2010; 38:97-109.

14. Trentesaux T, Rousset MM, Dehaynin E, Laumaillé M, Delfosse C. 15-year follow-up of a case of amelogenesis imperfecta: importance of psychological aspect and impact on quality of life. Eur Arch Paediatr Dent 2013; 14:47-51.

15. Astrøm AN, Mashoto K. Determinants of self-rated oral health status among school children in northern Tanzania. Int J Paediatr Dent 2002; 12: 90-100.

16. Do LG, Spencer A. Oral health-related quality of life of children by dental caries and fluorosis experience. J Public Health Dent 2007; 67:132-9.
17. Sundfeld RH, Croll TP, Briso AL, de Alexandre RS, Sundfeld Neto D. Considerations about enamel microabrasion after 18 years. Am J Dent 2007; 20:67-72.

18. Cocco AR, Lund RG, Torre E, Martos J Treatment of Fluorosis Spots Using a Resin Infiltration Technique: 14-month Follow-up. Oper Dent 2016; 41:357-62.

19. Muñoz MA, Arana-Gordillo LA, Gomes GM, Gomes $\mathrm{OM}$, Bombarda $\mathrm{NH}$, Reis $\mathrm{A}$, et al. Alternative esthetic management of fluorosis and hypoplasia stains: blending effect obtained with resin infiltration techniques. J Esthet Restor Dent 2013; 25:32-9.

20. Crombie F, Manton D, Palamara J, Reynolds E. Resin infiltration of developmentally hypomineralised enamel. Int J Paediatr Dent 2014; 24:51-5.

21. Torres $C R$, Borges $A B$. Color masking of developmental enamel defects: a case series. Oper Dent 2015; 40:25-33.

22. Fondriest $\mathrm{J}$ Shade matching in restorative dentistry: the science and strategies. Int J Periodontics Restorative Dent 2003; 23:467-79.

23. Cörekçi B, Irgın C, Malkoç S, Oztürk B. Effects of staining solutions on the discoloration of orthodontic adhesives: an in-vitro study. Am J Orthod Dentofacial Orthop 2010; 138:741-6.

24. Dozić A, Kleverlaan CJ, El-Zohairy A, Feilzer AJ, Khashayar G. Performance of five commercially available tooth color-measuring devices. J Prosthodont 2007; 16:93-100.

25. Browning WD, Chan DC, Blalock JS, Brackett MG. A comparison of human raters and an intra-oral spectrophotometer. Oper Dent 2009; 34:337-43.

26. Bilgiç $O$, Türker Ş. Diş hekimliği öğrencilerinin renk ölçüm başarılarının değerlendirilmesi. Atatürk Üniv Diş Hek Fak Derg 2015; 25.

27. Senestraro SV, Crowe JJ, Wang M, Vo A, Huang G, Ferracane $J$, et al. Minimally invasive resin infiltration of arrested white-spot lesions: a randomized clinical trial. J Am Dent Assoc 2013; 144: 997-1005.

28. Celik EU, Yildiz G, Yazkan B. Clinical evaluation of enamel microabrasion for the aesthetic management of mild-to-severe dental fluorosis. ] Esthet Restor Dent 2013; 25: 422-30. 
29. Sheoran N, Garg S, Damle SG, Dhindsa A, Opal S, Gupta S. Esthetic management of developmental enamel opacities in young permanent maxillary incisors with two microabrasion techniques--a split mouth study. J Esthet Restor Dent 2014; 26: 34552.

30. Hasegawa A, Ikeda I, Kawaguchi S. Color and translucency of in vivo natural central incisors. J Prosthet Dent 2000; 83:418-23.

31. Karamouzos A, Papadopoulos MA, Kolokithas G, Athanasiou $\mathrm{AE}$. Precision of in vivo spectrophotometric colour evaluation of natural teeth. J Oral Rehabil 2007; 34: 613-21.

32. Paul S, Peter A, Pietrobon $\mathrm{N}$, Hämmerle $\mathrm{CH}$. Visual and spectrophotometric shade analysis of human teeth. J Dent Res 2002; 81:578-82.

33. Paris S, Schwendicke F, Keltsch J, Dörfer C, Meyer-Lueckel $\mathrm{H}$. Masking of white spot lesions by resin infiltration in vitro. J Dent 2013; 41:e28-34.

34. Yetkiner $E$, Wegehaupt $F$, Wiegand A, Attin R, Attin T. Colour improvement and stability of white spot lesions following infiltration, micro-abrasion, or fluoride treatments in vitro. Eur J Orthod 2014; 36:595-602.

35. de Lacerda AJ, da Silva Ávila DM, Borges AB, Pucci CR, Rocha Gomes Torres C. Adhesive Systems as an Alternative Material for Color Masking of White Spot Lesions: Do They Work? J Adhes Dent 2016; 18:43-50.

36. Yuan H, Li J, Chen L, Cheng L, Cannon RD, Mei L. Esthetic comparison of white-spot lesion treatment modalities using spectrometry and fluorescence. Angle Orthod 2014; 84:343-9.

37. Gugnani N, Pandit IK, Gupta M, Josan R. Caries infiltration of noncavitated white spot lesions: A novel approach for immediate esthetic improvement. Contemp Clin Dent 2012; 3:S199202.

38. Büyük C. Opak lezyonlarda mikroabrazyon ve rezin infiltrasyon uygulamalarının klinik olarak değerlendirilmesi [Doktora tezi]. Ankara, Gazi Üniversitesi, 2015.

\author{
Yazışma Adresi \\ Mihriban Dudu Gizem Gençer \\ Hakkari Ağız ve Diş Sağlığı Merkezi, \\ Merkez/Hakkari, 30000, Türkiye
}

Telefon numarası: +90 (438) 2110932

e-mail adresi: md.gizemozbay@gmail.com 